\title{
Structural and cytological aspects of mango floral induction using paclobutrazol
}

\author{
Moacir Brito Oliveira ${ }^{\mathrm{a}}$, Maria Gabriela Ferreira Figueiredo ${ }^{\mathrm{b}}$, Marlon Cristian Toledo Pereira ${ }^{\mathrm{a}}$, \\ Maria Aparecida do Carmo Mouco ${ }^{c}$, Leonardo Monteiro Ribeiro ${ }^{\mathrm{b}, *}$, \\ Maria Olívia Mercadante-Simões ${ }^{\mathrm{b}}$ \\ ${ }^{a}$ Departamento de Ciências Agrárias, Universidade Estadual de Montes Claros, Janaúba, MG 39440-00, Brazil \\ ${ }^{\mathrm{b}}$ Departamento de Biologia Geral, Universidade Estadual de Montes Claros, Montes Claros, MG 39401-089, Brazil \\ ${ }^{\mathrm{c}}$ Empresa Brasileira de Pesquisa Agropecuária, Embrapa-Semiárido, Petrolina, PE, Brazil
}

\section{A R T I C L E I N F O}

\section{Keywords:}

Flowering control

Floral development

Flower ontogenesis

Mango production

\begin{abstract}
A B S T R A C T
Mango flowering induction using the gibberellin synthesis repressor paclobutrazol (PBZ) allows off-season production and two annual harvests under semiarid growing conditions. Structural and cytological changes in the stem apex and leaves resulting from the application of the PBZ technique are unknown, however, as are the patterns of development of reproductive structures. We sought to investigate the morphological, histological, and cytological aspects of floral induction in 'Palmer' mangos using PBZ, and to characterize its flowering in a semiarid region of Brazil. Anatomical evaluations of stem apices were performed, and ultrastructural and micromorphometric evaluations were made of leaves at 30,60 and 90 days after PBZ application, as well as under control conditions. The ontogenesis of the plant's inflorescence was characterized and flowering was described under field conditions. PBZ caused restrictions of cell expansion and the accumulation of both cells and phenolic compounds in the stem apex related to the transition to the reproductive phase. Floral induction does not provoke significant changes in leaf micromorphometry, although phenolic compounds, calcium oxalate crystals, and lipophilic substances accumulate in the mesophyll. Cell expansion and the formation of axillary buds at the stem apex indicate floral differentiation and the triggering of ontogenesis of the inflorescence, with the development of inflorescence axes and flowers. Flowering occurs in eight stages over 32 days, and the descriptions presented here should be useful for enhancing floral induction and mango orchard management.
\end{abstract}

\section{Introduction}

Mango tree flowering depends on changes in the developmental patterns of the stem apex from a vegetative to reproductive mode, and the ontogenesis of the inflorescence (Kinet, 1993; Ramírez and Davenport, 2010). Although there is still uncertainty concerning flowering control mechanisms, it is known that flowering can be induced by low temperatures (Reece et al., 1949; Batten and Mcconchie, 1995; Davenport, 2007), with water stress as a secondary stimulus (NúñezElisea and Davenport, 1994; Ramírez and Davenport, 2010). Techniques for floral induction in mangos have been developed in recent decades that involve the use of growth regulators such as paclobutrazol (PBZ) and uniconazole (UCZ) that block gibberellin synthesis and thus restrict vegetative development (Davenport, 2007; Ramírez and Davenport, 2010; Guevara et al., 2012).

The efficiency of mango floral induction through the use of growth regulators depends on controlling factors such as water availability and plant mineral nutrition (Ramírez and Davenport, 2010), which is favored in dry weather conditions. Studies in the semiarid region of northeastern Brazil have adapted floral induction techniques to irrigated crops (Mouco and Albuquerque, 2005) - allowing the staggering of fruit production with off-season and two annual harvests, resulting in significant economic gains (Faria et al., 2016). The floral differentiation processes of mango trees are complex and involve both anatomical and physiological changes to the buds and leaves of the apical branches (Davenport, 2007; Ramírez and Davenport, 2010). A more detailed knowledge of the structural changes related to flowering would favor improvements in flowering induction through management practices and the use of growth regulators. Despite the importance of commercial mango cultivation, that research is only incipient and covers only a limited number of varieties (Enciso et al., 2000; Osuna et al., 2000; Pérez et al., 2009; Palanichamy et al., 2012).

\footnotetext{
* Corresponding author.

E-mail address: leonardo.ribeiro@unimontes.br (L.M. Ribeiro).
} 
We therefore sought to evaluate the morphological, histological, and cytological aspects of floral induction associated with the use of PBZ in 'Palmer' mangos under semiarid conditions by: i) evaluating the effects of floral induction on the anatomy of the stem apex; ii) describing the micromorphometric and ultrastructural changes in mango leaves during floral induction; iii) characterizing the ontogenesis of the inflorescence; and, iv) morphologically characterizing flowering under field conditions.

\section{Materials and methods}

\subsection{Experimental area}

We conducted all of the experiments in a commercial orchard in the municipality of Janaúba in the northern region of Minas Gerais State, Brazil $\left(15^{\circ} 42^{\prime} 21^{\prime \prime} \mathrm{S} ; 43^{\circ} 18^{\prime} 39^{\prime \prime} \mathrm{W}\right.$, altitude $\left.472 \mathrm{~m}\right)$. The region has an Aw climate by the Köppen classification system, with a mean annual temperature of $23.7{ }^{\circ} \mathrm{C}$, and a mean annual rainfall rate of $830 \mathrm{~mm}$ (concentrated in the austral summer).

The three-year-old mango orchard was composed of 'Palmer' variety plants grafted onto 'Espada' rootstocks. The plants were spaced $4 \mathrm{~m}$ between rows and $2 \mathrm{~m}$ between plants, totaling 1200 plants.ha $^{-1}$. Five months before floral induction, the apical branches were pruned with shears, aiming at the uniformity of their length, as recommended by Mouco (2015). The last two vegetative flows were preserved, and each flow had approximately $40 \mathrm{~cm}$. The plants were irrigated by localized micro-sprinklers regulated by monitoring crop evapotranspiration.

\subsection{Floral induction}

Our experiments were carried out in a randomized block design with two treatments: floral induction using paclobutrazol (PBZ), and controls. Four replicates per treatment were used, each consisting of three plants. Floral induction was performed according to Albuquerque et al. (2002), with adaptations. We applied PBZ (Cultar ${ }^{\circledast}$ ) to the soil in a single dose of $1.0 \mathrm{~g}$ of active ingredient plant ${ }^{-1} \mathrm{~m}^{-1}$ of canopy when the plants demonstrated two vegetative flushings and the final episode was still immature. The control treatment plants did not receive PBZ application.

The following procedures were applied to both PBZ treated and control treatment plants. We gradually reduced irrigation 50 days after the application of the growth regulator (days after the beginning of induction: DAI) until reaching $50 \%$ of the volume required by the plant. From 50 DAI onwards, three applications of $3.0 \%$ potassium sulfate were made (by spraying on the leaves) every two weeks, with the final application being supplemented with etefon $\left(0.5 \mathrm{~mL} \mathrm{~L}^{-1}\right)$. We initiated weekly applications of $2.0 \%$ (w / v) calcium nitrate (by spraying on the leaves) at 100 DAI until the inflorescences became evident; irrigation was then normalized. In order to evaluate the efficiency of PBZ in floral induction, the percentage of branches with flowers were determined at 130 DAI.

Our study considered three phases of reproductive development, based on the management practice successfully employed on a large scale in the study region (unpublished data): i) induction, when the stem apex shifts from the vegetative to the reproductive development phase; ii) differentiation, when ontogenesis of the inflorescence occurs; and, iii) flowering, which encompasses all of the developmental phases of the inflorescence (Fig. 1).

\subsection{Morphological and histological evaluations of the stem apices during the induction phase}

We randomly selected five plants treated with PBZ and from the control treatment and collected one branch from each plant at 30, 60 and 90 DAI (Fig. 1). The materials were wrapped in damp cloth and packed in styrofoam boxes until sample preparation. We cut fragments approximately $2 \mathrm{~mm}$ long from the apical regions of the branches under a stereomicroscope; the most developed leaves and scales were removed for exposure of the stem apex. Samples for evaluation using scanning electron microscopy (SEM), were fixed in Karnovsky solution (Karnovsky, 1965), dehydrated in an ethanol series, and subjected to critical point drying in a dehydrator (Baltec CPD 0.0, Balzers, Liechtenstein, Germany) using $\mathrm{CO}_{2}$ as a drying medium. The materials were gold-plated in metallizer (MED 010, Balzers, Liechtenstein, Germany) and examined by scanning electron microscopy (Quantum 200, FEI Company, Eindhoven, Netherlands) with digital image captures at $12-20 \mathrm{kV}$ (Robbards, 1978).

For histological evaluation, the samples were fixed in Karnovsky's solution (Karnovsky, 1965) for $24 \mathrm{~h}$, dehydrated in an ethanol series, and cold-embedded in 2-(hydroxyethyl) methacrylate resin (Leica Microsystems, Heidelberg, Germany) (Paiva et al., 2011). Longitudinal sections (thickness $5 \mu \mathrm{m}$ ) were obtained using a rotating microtome (Atago, Tokyo, Japan), stained with $0.5 \%$ toluidine blue ( $\mathrm{pH} 4.7$ ) (O'Brien et al., 1964, modified), mounted on slides in permanent acrylic resin (Itacril, Itaquaquecetuba, Brazil), and analyzed using visible light microscope (Axio Scope A.1/Axiocam 105 color, Zeiss, Jena, Germany).

\subsection{Histological, ultrastructural, and micromorphological evaluations of apical leaves during the induction phase}

Ten fully expanded leaves from each of the branches from which the stem apexes were evaluated (one branch of each of five plants of each treatment - as previously described) were collected at 30, 60 and 90 DAI (Fig. 1). The materials were wrapped in damp cloth and packed in styrofoam boxes until sample preparation. Samples (fragments of $2 \times 2$ $\mathrm{mm}$ ) of the median leaf region were sectioned, under a stereomicroscope, for histological evaluation, as described above.

We used the images obtained in the histological analyzes for quantitative micromorphological evaluations in a completely randomized design, with five replications of 10 leaves per treatment; each replicate was photographed in ten fields. Image analyses were performed using Image-Pro Plus software (Media Cybernetics, Rockville, USA). We quantified the thicknesses of the epidermises of the adaxial and abaxial faces as well as the palisade and spongy parenchyma layers. Data were subjected to analysis of variance using SAS version 8 software (SAS Institute, North Carolina, USA); treatment averages were compared by Tukey test at a $5 \%$ level of probability.

We cut fragments (edges approximately $0.4 \mathrm{~mm}$ ) from the median leaf region (under a stereomicroscope) for ultrastructural analysis. The material was fixed in Karnovsky solution, pH 7.2 (Karnovsky, 1965), postfixed in a $1 \%$ osmium tetroxide solution (prepared with $0.1 \mathrm{M}$ phosphate buffer, $\mathrm{pH}$ 7.2), dehydrated in an ethanol series with subsequent acetone dehydration (twice for $30 \mathrm{~min}$ each), and embedded in Araldite resin (Leica Microsystems, Heidelberg, Germany). Sections 50 $\mathrm{nm}$ thick were cut using an ultramicrotome (EM FC6, Leica Microsystems, Heidelberg, Germany), contrasted in an uranyl acetate and lead citrate solution (Robbards, 1978; Roland, 1978), and examined using a transmission electron microscope (TEM) (CM 100, Philips / FEI Corporation, Eindhoven, The Netherlands) at $80 \mathrm{kV}$.

\subsection{Morphological and histological characterizations of the stem apex during floral differentiation}

We collected five stem apexes in the differentiation phase at 3, 7, 10 and 13 days (Fig. 1) and prepared them as described above for morphological evaluations by SEM and histological evaluations using light microscopy.

\subsection{Morphological characterization of flowering}

We undertook field observations every four days during the phase of inflorescence development (Fig. 1). Observations were initiated when 
Vegetative development

Control

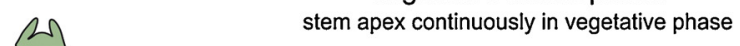

stem apex continuously in vegetative phase

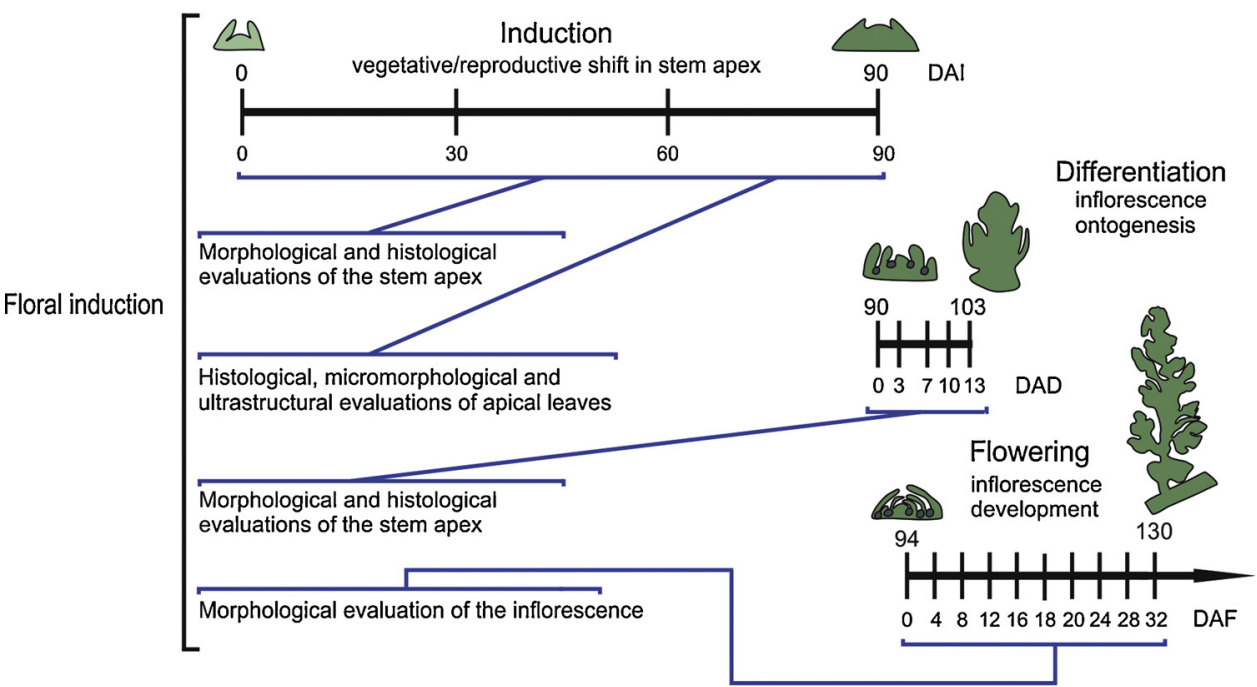

Fig. 1. Schematic illustrations of the appearance of the stem apex during the floral induction phases of mango plants using PBZ and control condition, highlighting sample collection times and the evaluations performed. DAI, days after the beginning of induction; DAD, days after the beginning of inflorescence differentiation; DAF, days after the onset of flowering. the plants evidenced swollen buds, and continued until the inflorescences completed approximately $50 \%$ of anthesis. We randomly collected branches during those observations for detailed morphological descriptions in the laboratory, using a stereomicroscope. The branch lengths were recorded, photographed, and described, based on work by Pérez et al. (2009) with the "Tommy Atkins" mango.

\section{Results}

After 130 DAI, $100 \%$ and $9 \%$ of the branches in the PBZ and control treatments, respectively, produced flowers, which attested to the efficiency of floral induction.

\subsection{Structural organization of the stem apex during the induction phase}

The stem apices of mango trees are covered by scales (which were removed in the processing of the evaluated material) and imbricated leaf primordia that have numerous trichomes on their surfaces (Fig. 2a). In their initial condition, the stem apices present a conformation common to dicotyledons, with a dome-shaped shoot meristem flanked by younger leaf primordia (Fig. 2b). The meristematic cells are globular and compactly arranged, with a prominent nucleus and dense cytoplasm (Fig. 2c). It was possible to identify procambial strands establishing the pre-vasculature of the leaf primordia, and the medullary region (adjacent to the stem apex) was composed of cells that showed early accumulations of phenolic compounds (arrowheads in Fig. 2b-c). The shoot meristem could be divided into layers according to the division plains of its cells: the most peripheral layer (L1) evidenced anticlinal divisions; the adjacent layer (L2) evidenced predominantly anticlinal divisions; the third layer (L3) showed both anticlinal and periclinal divisions (Fig. 2c). It was also possible to identify meristematic regions adjacent to the shoot meristem, with those peripheral meristems being formed by the cells derived from L1 and L2, and the internal medullary meristem being formed by cells derived from L3. No significant anatomical differences were observed at 30,60 and 90 DAI between control plants.

During the induction phase (Fig. 1a), at 60 DAI, the stem apex of the PBZ-treated plants evidenced swelling and lateral expansion (Fig. 2d-e). Their meristematic domes were flatter and phenolic compound accumulation had increased in the medullary region adjacent to the stem apex (Fig. 2e). The shoot meristem and adjacent meristematic regions were thickened due to the accumulation of cells originating from divisions, but not yet expanded (Fig. 2f). At 90 DAI, swelling of the stem apex had increased (Fig. 2g), the shoot meristem had lost its dome shape due to flattening, and increased accumulations of phenolic compounds were evident in the medullary region (Fig. 2h). Cell clustering could be observed in the shoot meristem and adjacent meristematic regions, with typical division planes in each location, but without cell expansion (Fig. 2i).

3.2. Histological, micromorphological, and ultrastructural changes in apical leaves during the induction phase

The apical leaves of the mango tree have an epidermis composed of irregularly shaped cells, with stomata concentrated on the abaxial face (Fig. 3a). The chlorophyll-parenchyma has a dorsiventral organization, with a stratified palisade parenchyma and a spongy parenchyma with 7-9 cell layers. The palisade parenchyma cells and palisade parenchyma layers adjacent to the abaxial face of the epidermis accumulate phenolic compounds (as evidenced by the toluidine blue histochemical test); the palisade parenchyma cells and spongy parenchyma cells adjacent to the abaxial face of the epidermis likewise accumulate phenolic compounds. Collateral vascular bundles of various dimensions can be seen distributed along the mesophyll. No significant differences were observed between the control and PBZ treatments until 60 DAI.

Although most of the anatomical features described above have not changed, at 90 DAI the palisade parenchyma of the apical leaves in plants treated with PBZ showed higher concentration of phenolic compounds than control plants (Fig. 3a-b). The leaves of plants treated with PBZ also showed more calcium oxalate crystals (concentrated in the regions adjacent to the vascular bundle).

Micromorphometric evaluations of the leaves showed increasing thickness of the abaxial face of the epidermis and the palisade and spongy parenchyma over time in both treatments (data not shown). The epidermis of the adaxial face did not significantly change during the evaluation period, although it was thicker $(\mathrm{P}<0.0001)$ in the control condition $(30.34 \mu \mathrm{m})$ than in the PBZ treatment $(26.61 \mu \mathrm{m})$ at $90 \mathrm{DAI}$ (Fig. 3a-b). The other characteristics evaluated were not influenced by floral induction with PBZ (data not shown).

The ultrastructural evaluations of the control treatment leaves at 90 DAI showed starch accumulation in the palisade parenchyma cell chloroplasts, which had well-developed thylakoids (Fig. 4a-b). 


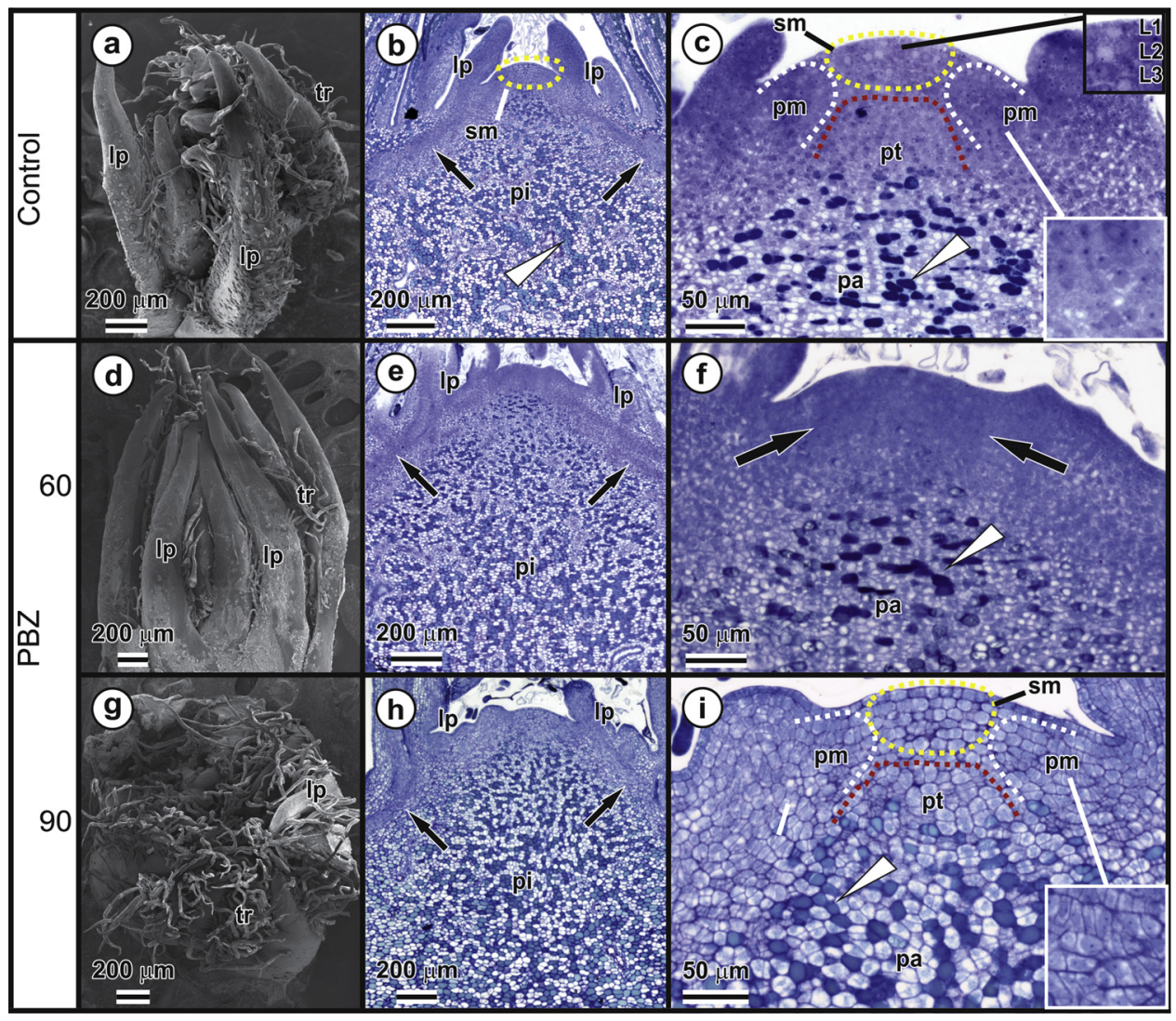

Fig. 2. SEM images and histological sections of 'Palmer' mango stem apices from plants under control condition and plants subjected to floral induction (by PBZ) at 60 and 90 days DAI. (a) Stem apex covered by leaf primordia with numerous trichomes. (b) Stem apex, highlighting the location of the shoot meristem, procambial strands (arrows), and cells with accumulations of phenolic compounds in the medullary region (arrowhead). (c) Stem apex, showing the location of the shoot meristem and adjacent meristematic regions and cells with accumulations of phenolic compounds in the medullary region (arrowhead), highlighting the the layers of the shoot meristem (square in the upper right corner) and shapes of the peripheral meristem cells (square in the lower right corner). (d) Stem apex, showing swelling and lateral expansion in relation to the control. (e) Stem apex, showing the flattened shoot meristem and highlighting procambial strands (arrows). (f) Stem apex, showing the dense concentration of compactly arranged cells in the meristematic region (arrows), and cells with accumulations of phenolic compounds in the medullary region (arrowhead). (g) Stem apex in frontal view, showing significant swelling. (h) Stem apex, showing the flattening of the apical meristem, procambial strands (arrows), and significant accumulations of phenolic compounds in the medullary region. (i) Stem apex, showing the shoot meristem and adjacent meristematic regions, and highlighting the agglomeration of non-expanded

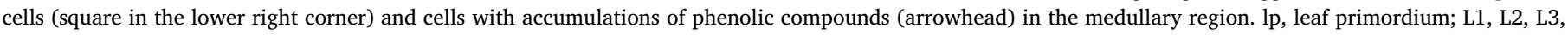

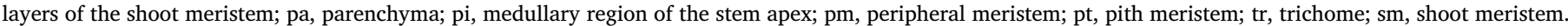

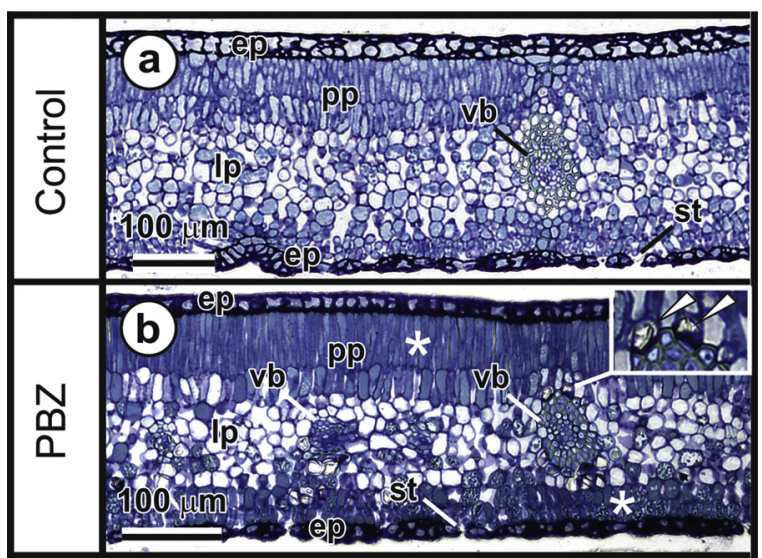

Fig. 3. Histological cross-sections of the mango leaf blade. (a) Leaf of a control plant at 90 DAI. (b) Leaf of a plant submitted to floral induction (by PBZ) at 90 DAI, highlighting the accumulation of phenolic compounds (asterisk) in the parenchyma and calcium oxalate crystals associated with the vascular bundle (arrowheads). ep, epidermis; lp, spongy parenchyma; pp, palisade parenchyma; st, stomata; vb, vascular bundle.

Phenolic compounds were widely distributed in the vacuoles of the palisade cells of leaves in the PBZ treatment (Fig. 4c-d). The thylakoid membranes of those chloroplasts were less well organized, without starch, but with accumulations of lipophilic substances.

\subsection{Structural organization of the stem apex during inflorescence differentiation}

The stem apex appeared expanded and flattened three days after the beginning of floral differentiation (DAD) (Fig. 5a-b) and there were notably active meristematic regions surrounded by leaf primordia that constituted axillary buds (Fig. 5b). The cells in regions adjacent to the shoot meristem, which had been compact and unexpanded at the end of the induction phase, now appeared significantly expanded (compare Fig. $2 \mathrm{i}$ and $5 \mathrm{~b}$ ). The onset of inflorescence apical growth was observed at $7 \mathrm{DAD}$, with significant shoot meristem activity (compare Fig. 5c and a). Vascular cylinders in the secondary axes of the inflorescences were differentiating in the regions adjacent to the inflorescence apex, with the proliferation of secretory channels in the main axis (Fig. 5d). Differentiation of the bracts from the leaf primordia was observed at 10 DAD (Fig. 5e), and the inflorescence had assumed its typical architecture, with expanding main and secondary axes (Fig. 5f). The bracts had expanded and were covered with trichomes at 13 DAD; the apical meristem continued its growth (Fig. 5g). Tertiary axes had emerged from the older secondary axes, and it was possible to observe the differentiation of the first flowers, already with both infertile (sepals and petals) and fertile (stamens and carpels - which had conspicuous ovaries and ovules) whorls (Fig. 5h).

\subsection{Morphological characterization of flowering}

Stage 1 of flowering under field conditions was characterized by the swelling of the apical bud (which is protected by scales and leaf primordia) at 4 days after flowering (DAF), and the average length of the main axis was approximately $30 \mathrm{~mm}$ (Fig. 6a-b). In stage 2 (8 DAF), the main axis of the inflorescence (covered by numerous elongated bracts) was observed to have grown (Fig. 6c-d). In stage 3 (12 DAF), the main axis of inflorescence becomes longer and the older bracts showed apical darkening, indicating senescence (Fig. 6e-f). In stage 4 (16 DAF), the development of the secondary axes of the inflorescence and the abscission of older bracts was observed (Fig. $6 \mathrm{~g}-\mathrm{h}$ ). At stage 5 (20 DAF), 


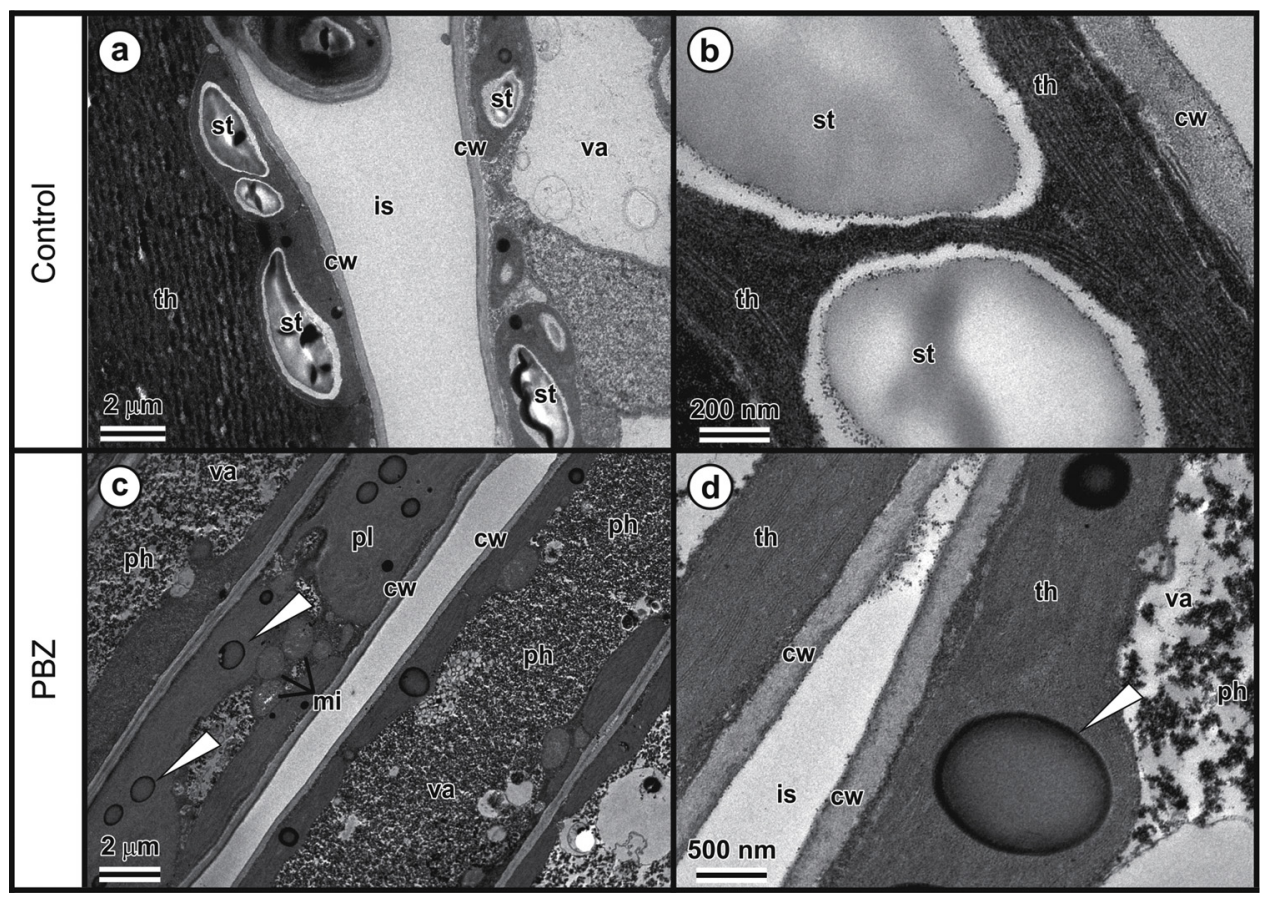

Fig. 4. TEM images of palisade parenchyma cells from mango leaves under control conditions and from a plant submitted to floral induction (by PBZ) at 90 DAI. (a) Peripheral regions of adjacent cells. (b) Peripheral region of the cell, showing a chloroplast with thickened thylakoids and starch grains. (c) and (d) Peripheral regions of adjacent cells, highlighting accumulations of lipophilic substances (arrowheads). cw, cell wall; is, intercellular space; mi, mitochondria; ph: phenolic compounds; pl: plastid; st: starch; th: thylakoids; va: vacuole.

most of the bracts had abscised and the secondary axes showed significant growth, giving the inflorescence the appearance of a panicle (Fig. $6 \mathrm{i}-\mathrm{j}$ ). In stage 6 (24 DAF), the elongation of the main and secondary axes continue, and the tertiary axes of inflorescence are observed developing (Fig. 6k-1). Stage 7 (28 DAF) is characterized by the full development of the main, secondary, and tertiary axes (Fig. $6 m-n$ ), and flowers are visible (inserted into the tertiary axes of inflorescence) but still closed. In Phase 8 (32 DAF), full bloom is observed, with anthesis of most flowers (Fig. 6o-p); in that stage, the average length of the main axis of the inflorescence was $50 \mathrm{~cm}$.

\section{Discussion}

This is the first report integrating structural and cytological aspects of mango flower induction using growth regulators. We characterized, for the 'Palmer' variety under semiarid conditions in Brazil, both the long phase (90 days, related to switching from a vegetative stage to reproductive status of the stem apex) and the fast phase (32 days) of flowering (Fig. 1). The descriptions presented should be useful for improving floral induction techniques and mango crop management.

\subsection{Effects of induction on stem apex anatomy}

Floral induction by PBZ is associated with the restriction of cell expansion and the accumulation of phenolic compounds in the stem apex. We observed cell clustering at the apex produced by cell division at the end of the induction phase (90 DAI), but not cell expansion - a situation related to the inhibition of gibberellin biosynthesis (GAs) by PBZ. The similarity between PBZ and ent-caurene (one of the intermediate compounds in GA biosynthesis) results in PBZ being preferentially used in that biosynthetic pathway - which restricts hormone production and reduces its concentration in plant tissues (Böse et al., 1992; Upreti et al., 2013). As GAs promote cell elongation and negatively regulate flowering in mango plants, reducing their levels is thought to stimulate florigenic promoters and favor reproductive differentiation (Davenport, 2007; Ramírez and Davenport, 2010; Guevara et al., 2012). Reductions in GA4, GA3, GA7 and GA1 levels, associated with increased $\mathrm{ABA}$ and cytokinins concentrations, were evidenced in PBZ-treated mango shoot apices (Upreti et al., 2013). Our results allow us to propose that structural aspects must also be considered to fully understand the effects of PBZ. The conversion of vegetative meristems to floral meristems is a complex process that depends on intense signaling between stem apex cells, which is controlled by cell position and distribution patterns (Thomson et al., 2017). In the case of mango floral induction, the accumulation of non-expanded cells in the stem apex (due to hormonal alterations promoted by PBZ) appears to interfere with cell signaling and contribute to reproductive differentiation.

Srilatha et al. (2015) observed a correlation between increased phenolic compound contents and the flowering intensity of mango trees. The observed increases in phenolic contents may not be a direct effect of PBZ on phenol biosynthesis, but may reflect an unidentified regulator, as suggested by Rademacher (2000). High levels of phenolic compounds can act as growth inhibitors through their negative effects on cell division and elongation (Wink, 2008; Srilatha et al., 2015). Future studies may shed light on how accumulations of unexpanded cells and phenolic compounds at the stem apex are associated with flowering processes in mango plants.

\subsection{Micromorphometric and ultrastructural responses of leaves during floral induction}

There were no significant changes in leaf micromorphometry in relation to the control condition during floral induction using PBZ, but the absence of starch and accumulations of phenolic compounds, calcium oxalate crystals, and lipophilic substances in the mesophyll were notable. The production of phenolic compounds has been associated with protective functions in plants during abiotic stress (Wink, 2008; Demarco, 2017), but there have been no studies relating the production of those leaf compounds to PBZ exposure. The biological function of calcium oxalate crystals in plants is not well understood, and may be related to calcium metabolism (Paiva, 2019) and storage (Nakata, 2003), or protection against herbivores (Molano-Flores, 2001). Calcium oxalate accumulation in regions adjacent to the vessels has been reported in many species, as the entry of calcium into plants (a poorly mobile mineral) occurs through the xylem (Paiva, 2019). Little is known about the role of calcium accumulation at cellular or tissue levels in mangoes, although Burondkar et al. (2009) associated greater calcium absorption with PBZ exposure. PBZ applications have been 


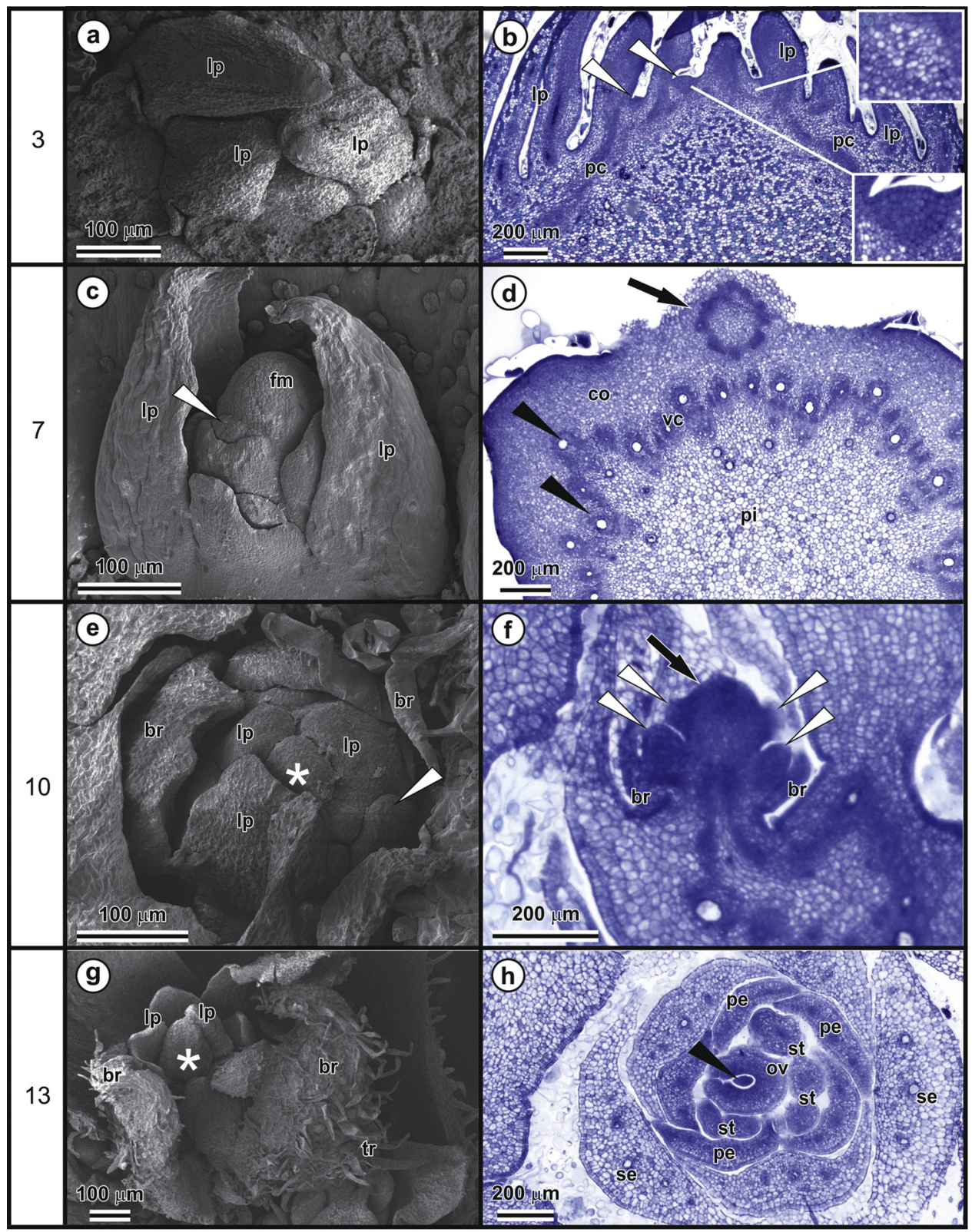

Fig. 5. SEM images and histological sections of the mango stem apex at different times of inflorescence differentiation. The numbers in the left-hand column indicate days after the beginning of inflorescence differentiation (DAD). (b, f) Longitudinal sections. (d, -h) Cross sections. (a) Frontal view of the expanded stem apex, with no obvious differences from the vegetative phase. (b) Stem apex, showing alterations indicative of the beginning of floral differentiation: significant flattening, the presence of meristems showing intense activity in the leaf primordial axilla (arrowheads and rectangle in the lower -right corner) and the expansion of cells adjacent to the shoot meristem (rectangle in the top right corner). (c) Inflorescence apex, showing the growth of leaf primordia, and highlighting a bud that will develop on the secondary axis of the inflorescence (arrowhead). (d) Main axis of the inflorescence with an eustelic organization pattern, highlighting a vascular trace of the secondary axis (arrow) and secretory channels (arrowheads) associated with the vascular cylinder. (e) Apex of the inflorescence, showing differentiating bracts, a conical meristem (asterisk), and the apex of the secondary axis (arrowhead). (f) Inflorescence, highlighting the meristem of the main axis (black arrow) and the meristems of the secondary axes (arrowheads). (g) Apex of the inflorescence, enveloped by bracts with numerous trichomes, highlighting the conical apical meristem (asterisk) flanked by leaf primordia. (h) Flower developing infertile (sepals and petals) and fertile (carpel and stamen) whorls, with emphasis on the ovule (arrowhead). br, bracts; co, cortex; fm, inflorescence meristem; lp, leaf primordia; ov, -ovary; pc, procambium; pe, petals; pi, pith; se, sepals; st, stamens; tr, trichomes; vc, vascular cylinder.

reported to contribute to maintaining chloroplast structural integrity under water stress conditions (conditions also associated with stimulating the antioxidant system and the synthesis of lipophilic substances) (Soumya, 2014).

Several studies have shown that the accumulation of inducers in the apical leaves and their transfer to target cells in the shoot meristem is determinant for the transition of the stem apex from a vegetative to a reproductive status (reviewed by Ramírez and Davenport, 2010). Our results showed that visible histochemical differences between flowering-induced plant leaves and control leaves occur only after 90 DAI which corroborates the proposal that gradual changes occur in those organs. Considering that phenolic compounds are present in large amounts in both leaves and the stem apex, and that calcium is poorly mobile in plants (Paiva, 2019), it is possible to suggest that starch consumption and lipophilic accumulations are related to the accumulation of flowering inducers in leaves.

\subsection{Anatomical characterization of floral differentiation and flowering morphology}

The ontogenesis of 'Palmer' mango inflorescences under semiarid conditions occurs within 13 days after the beginning of floral differentiation (90 to $103 \mathrm{DAI}$ ), with the formation of the principal and secondary axes of the inflorescence and the development of the first flowers (Fig. 1). Stem apex enlargement and meristematic activity in the axils of adjacent leaf primordia (related to the formation of the secondary axes of the inflorescence) are considered anatomical markers of mango floral differentiation (Ravishankar et al., 1979; Osuna et al., 2000; Pérez et al., 2009; Davenport, 2007). We have shown here that, in the case of floral induction using PBZ, cell expansion in the stem apex can be considered an additional marker.

It is consensual that a rapid period of ontogenesis and the development of the mango inflorescence follows a long period of induction (Ravishankar et al., 1979; Kinet, 1993; Davenport, 2007). The stem apex (initially dome-like), becomes conical, and gradually gives rise to the secondary and tertiary axes of the inflorescences and the flowers themselves (Kinet, 1993; Palanichamy et al., 2012). Our results indicate 


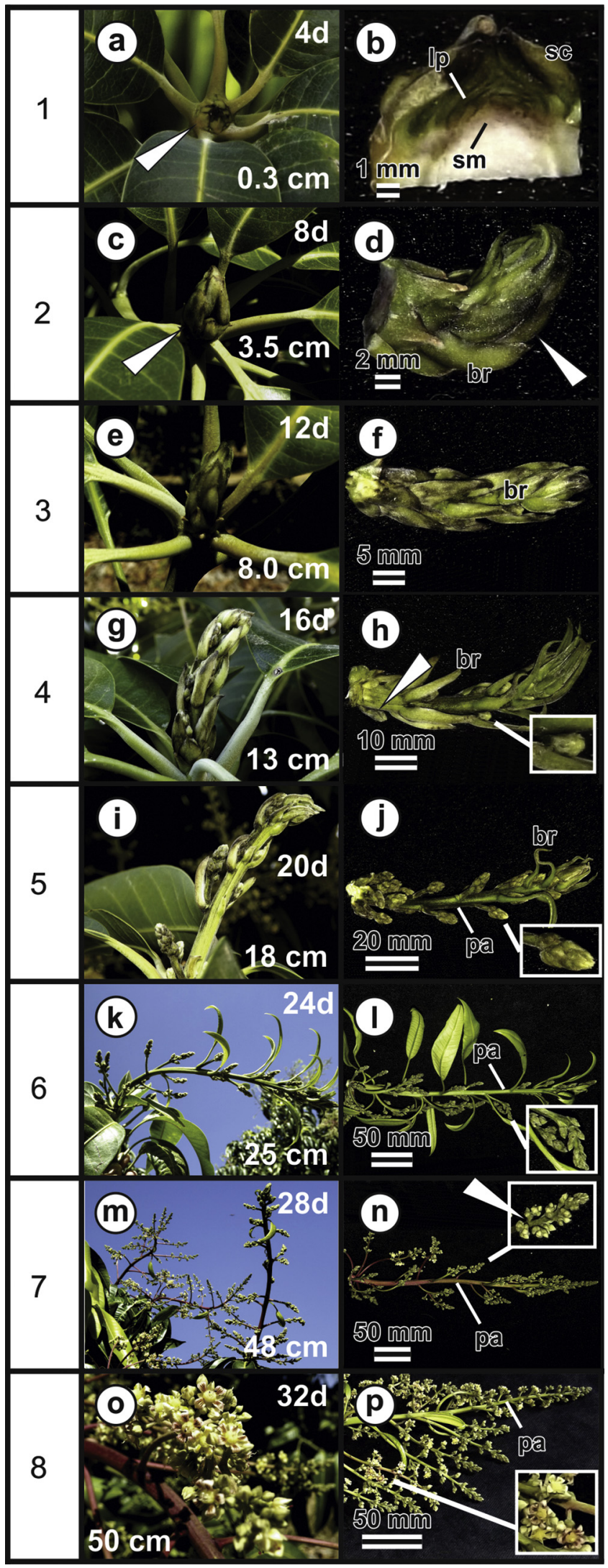

that the ontogenetic pattern of inflorescence following floral induction by PBZ does not demonstrate significant variations in relation to the steps that occur under natural conditions (comparing reports by
Fig. 6. Morphology of a "Palmer" mango inflorescence developed under semiarid conditions. The numbers in the left-hand column indicate the stages of inflorescence development. In the second column, the numbers in the upper right-hand corner indicate the days after flowering began (DAF). (a-b) Swollen buds (arrowhead) covered by scales and leaf primordia. (c-d) Early inflorescence growth, covered by elongated bracts (arrowhead). (e-f) Main axis of the inflorescence, with bracts covering the buds of the secondary axes. $(\mathrm{g}-\mathrm{h})$ Inflorescence, with loss of part of bracts and evidence of the development of secondary axes (arrowhead, and rectangle in the lower right corner). (i-j) Obvious secondary axes (rectangle in the lower right corner) and panicle formation. (k-1) Panicle with elongated secondary axes and evidence of tertiary axis development (rectangle in the lower right corner). (m-n) Panicle in full development, with evident internodes of the tertiary axes (arrowhead) with still unopened flowers. (o-p) Panicle showing the anthesis of most of its flowers. br, bracts; lp, leaf primordia; pa, panicle; sc, scale; sm, shoot meristem.

Ravishankar et al., 1979; Osuna et al., 2000; Pérez et al., 2009; Palanichamy et al., 2012). It is noteworthy, however, that the period between the onset of inflorescence differentiation and the development of fertile whorls (carpel and stamens), as well as the total flowering period (up to anthesis), appear to be shorter after PBZ treatment. As plant phenology is controlled by both genetic and environmental factors, it will be necessary to structurally characterize the processes of floral induction in the principal mango varieties under different cultivation conditions in order to improve crop management techniques.

\subsection{Conclusions}

Based on the results obtained here with 'Palmer' mango floral induction using PBZ under semiarid conditions, we can conclude that: i) PBZ inhibits the expansion of the meristematic cells of the stem apex and induces apex thickening and the accumulation of phenolic compounds; ii) the application of PBZ results, at the cellular level, in reductions of starch reserves, and accumulations of calcium oxalate crystals, phenolic compounds, and lipophilic substances in the mesophyll; iii) floral differentiation requires 13 days (starting 103 days after PBZ application), with the formation of inflorescence axes and flowers; iv) flowering occurs in eight stages over 32 days, beginning with the swelling of the apical bud and ending with anthesis of most flowers.

\section{Author contributions statement}

MBO, LMR, MOMS and MACM conceived and designed the research; MBO, MCTP and MACM conducted the experiments and field evaluations; MGFF, MOMS and LMR, conducted the morphological and anatomical evaluations; MOMS conducted the ultrastructural evaluations; MBO drafted the initial text; MCTP, LMR, MOMS and MACM revised the manuscript.

\section{Declaration of Competing Interest}

The authors declare that they have no conflicts of interest.

\section{Acknowledgments}

The authors thank the Microscopy Center of the Universidade Federal de Minas Gerais-UFMG for electron and scanning microscopy analyses, and Fazenda Piranhas for the physical structures to conduct the experiments and analyses. We also acknowledge the financial support provided by Mangaclara Consultoria em Fruticulturaand the research productivity grants offered by the Conselho Nacional de Desenvolvimento Científico e Tecnológico - CNPqto MCTP, LMR and MOMS. 


\section{References}

Albuquerque, J.A.S., Medina, V.D., Mouco, M.A., Do, C., 2002. Indução floral. In: Genu, P.J.C., Pinto, C.A.Q. (Eds.), A cultura da mangueira. Embrapa Informação Tecnológica, Brasilia, pp. 259-276.

Batten, D., Mcconchie, C., 1995. Floral induction in growing buds of lychee (Litchi chinensis) and mango (Mangifera indica). Funct. Plant Biol. 22, 783. https://doi.org/10. 1071/PP9950783.

Böse, G., Graebe, J.E., Grosselindemann, E., Hedden, P., Aach, H., Schweimer, A., Sydow, S., Lange, T., 1992. The biosynthesis of ent-kaurene in germinating seeds and the function of 2-oxoglutarate in gibberellin biosynthesis. In: Karssen, C.M., van Loon, L.C., Vreugdenhil, D. (Eds.), Progress in Plant Growth Regulation. Springer Netherlands, Dordrecht, pp. 545-554. https://doi.org/10.1007/978-94-011-2458$4 \_65$.

Burondkar, M.M., Jadhav, B.B., Chetti, M.B., 2009. Effect of plant growth regulators, polyamine and nutrients on fruit quality and occurrence of spongy tissue in alphonso mango. Acta Hortic. 689-696. https://doi.org/10.17660/ActaHortic.2009.820.85.

Davenport, T.L., 2007. Reproductive physiology of mango. Braz. J. Plant Physiol. 19, 363-376. https://doi.org/10.1590/S1677-04202007000400007.

Demarco, D., 2017. Histochemical analysis of plant secretory structures. In: Pellicciari, C., Biggiogera, M. (Eds.), Histochemistry of Single Molecules. Springer, New York, New York, NY, pp. 313-330. https://doi.org/10.1007/978-1-4939-6788-9_24.

Enciso, T., Engleman, E., Román, A., 2000. Iniciación y diferenciación floral en mango manila. Agrociencia 34, 573-581.

Faria, L.N., Soares, A.A., Donato, S.L.R., Santos, M.Rdos, Castro, L.G., 2016. The effects of irrigation management on floral induction of "Tommy Atkins" mango in bahia semiarid. Eng. Agríc. 36, 387-398. https://doi.org/10.1590/1809-4430-Eng.Agric. v36n3p387-398/2016.

Guevara, E., Jiménez, V.M., Bangerth, F.K., 2012. Response of endogenous hormone concentrations to two floral inductive treatments, viz. KNO3 and PBZ, in Mango cv. 'Tommy Atkins' growing under tropical conditions. Trop. Plant Biol. 5, 253-260. https://doi.org/10.1007/s12042-012-9107-8.

Karnovsky, M.J.A., 1965. formaldehyde-glutaraldehyde fixative of righ osmolality for use in electron microscopy. J. Cell Biol. 27, 137.

Kinet, J.M., 1993. Environmental, chemical, and genetic control of flowering. Horticult. Rev. 15, 279-334.

Molano-Flores, B., 2001. Herbivory and calcium concentrations affect calcium oxalate crystal formation in leaves of sida (Malvaceae). Ann. Bot. 88, 387-391. https://doi. org/10.1006/anbo.2001.1492.

Mouco, M.A.C., 2015. Cultivo da mangueira. EMBRAPA, Petrolina.

Mouco, M.A.C., Albuquerque, J.A.S., 2005. Efeito do paclobutrazol em duas epocas de produção da mangueira. Bragantia 64, 219-225.

Nakata, P.A., 2003. Advances in our understanding of calcium oxalate crystal formation and function in plants. Plant Sci. 164, 901-909. https://doi.org/10.1016/S01689452(03)00120-1.

Núñez-Elisea, R., Davenport, T.L., 1994. Flowering of mango trees in containers as influenced by seasonal temperature and water stress. Sci. Hortic. 58, 57-66. https:// doi.org/10.1016/0304-4238(94)90127-9.
O'Brien, T.P., Feder, N., McCully, M.E., 1964. Polychromatic staining of plant cell walls by toluidine blue O. Protoplasma 59, 368-373. https://doi.org/10.1007/ BF01248568.

Osuna, T.E.M., Engleman, A.E., Becerril, R., Mosqueda, M., Soto, M.H., Castillo, A.M., 2000. Iniciación y diferenciación floral en mango 'Manila'. Agrociencia 34, 573-581.

Paiva, E.A.S., 2019. Are calcium oxalate crystals a dynamic calcium store in plants? New Phytol. 223, 1707-1711. https://doi.org/10.1111/nph.15912.

Paiva, É., Pinho, S.Z., Oliveira, D.M.T., 2011. Large plant samples: how to process for GMA embedding? In: Chiarini-Garcia, H., Melo, R.C.N. (Eds.), Light Microscopy: Methods and Protocols. Humana Press, Totowa, pp. 37-49.

Palanichamy, V., Reddy, N.N., Babu, S., Selvaraj, E., Aranganathan, B.M., 2012. Determination of time period of fruit bud differentiation and the associated histological and biochemical changes in mango hybrids. Res J Pharm Bio Chem Sci 31, $271-289$.

Pérez, B.M.H., Vázquez, V.V., Osuna, G.J.A., 2009. Floral bud development of 'Tommy Atkis' mango under tropical condition in Nayarit, Mexico. Acta Hortic. 820, 197-204.

Rademacher, W., 2000. Growth r etardants: effects on gibberellin biosynthesis and other metabolic pathways. Annu. Rev. Plant Physiol. Plant Mol. Biol. 51, 501-531. https:// doi.org/10.1146/annurev.arplant.51.1.501.

Ramírez, F., Davenport, T.L., 2010. Mango (Mangifera indica L.) flowering physiology. Acta Sci. Pol. Hortorum Cultus 126, 65-72. https://doi.org/10.1016/j.scienta.2010. 06.024.

Ravishankar, H., Rao, M.M., Bojappa, K.M., 1979. Fruit-bud differentiation in mango 'Alphonso' and 'Totapuri' under mild tropical rainy conditions. Scientia Hort. 10, 95-99.

Reece, P.C., Furr, J.R., Cooper, W.C., 1949. Further studies of floral induction in the Haden mango. Am. J. Bot. 36, 734-740.

Robbards, A.W., 1978. An introduction to techniques for scanning electron microscopy of plant cells. In: Hall, J.L. (Ed.), Electron Microscopy and Cytochemistry of Plant Cells. Elsevier, New York, pp. 343-403.

Roland, A.M., 1978. General preparations and staining of thin sections. In: Hall, J.L. (Ed.), Electron Microscopy and Cytochemistry of Plant Cells. Elsevier, New York, pp. 1-62.

Soumya, P.R., 2014. Role of Paclobutrazol in Amelioration of Water Deficit Stress in Chickpea (Cicer arietinum L.). M.SC. Thesis. ICAR-Indian Agricultural Research Institute, New Delhi.

Srilatha, V., Reddy, Y.T.N., Upreti, K.K., Jagannath, S., 2015. Pruning and paclobutrazol induced vigour, flowering and hormonal changes in mango (Mangifera indica L.). The Bioscan 10, 161-166.

Thomson, B., Zheng, B., Wellmer, F., 2017. Floral organogenesis: when knowing your ABCs is not enough. Plant Physiol. 173, 56-64. https://doi.org/10.1104/pp.16. 01288.

Upreti, K.K., Reddy, Y.T.N., Prasad, S.R.S., Bindu, G.V., Jayaram, H.L., Rajan, S., 2013. Hormonal changes in response to paclobutrazol induced early flowering in mango cv. Totapuri. Scientia Horticulturae 150, 414-418. https://doi.org/10.1016/j.scienta. 2012.11.030.

Wink, M., 2008. Plant secondary metabolism: diversity, function and its evolution. Nat. Prod. Commun. 3, 1934578X0800300. https://doi.org/10.1177/ $1934578 X 0800300801$. 